\title{
EPIDEMIOLOGICAL PROFILE OF PATIENTS HOSPITALIZED IN A NEONATAL INTENSIVE CARE UNIT
}

\author{
PERFIL EPIDEMIOLóGICO DE P ACIENTES INTERNADOS EM UMA \\ UNIDADE DE TERAPIA INTENSIVA NEONATAL \\ Epidemiological profile in a NICU
}

\author{
Maryana Neves de Souza ${ }^{1}$, Eduardo Shimoda ${ }^{2}$,Shaytner Campos Duarte ${ }^{3 *}$. \\ ${ }^{1}$ Faculdade de Medicina de Campos - FMC, Campos dos Goytacazes, Rio de Janeiro \\ ${ }^{2}$ Universidade Candido Mendes - UCAM, Campos dos Goytacazes, Rio de Janeiro \\ ${ }^{3}$ Faculdade de Medicina de Campos - FMC, Campos dos Goytacazes, Rio de Janeiro \\ *autor contact email: shaytnercampos@hotmail.com
}

\begin{abstract}
The infant mortality (IM) is caused due to a combination of biological, cultural, social events and flaws in the health system. In Brazil, it's possible to observe that the control of IM is not yet evident. This study aimed to identify the main causes of hospitalization in a Neonatal Intensive Care Unit in 2012 and stratify their characteristics. This was a documentary crosssectional observational study. 393 medical records were analyzed by the discharge neonatal summary and official data of deaths, made from January 2012 to December of 2012. The data were tabulated with the program "Originlab data analysis" and formatted in the Excel program. Prematurity was the main cause of hospitalization and neonatal death identified at work. Low birth weight, gestational age less than 34 weeks and the length of hospital stay were also analyzed characteristics favoring an increases risk of death. Efforts to better stratification of data from national epidemiological profiles are important for better attention to this age group.
\end{abstract}

Keywords: Infant Mortality; Epidemiological profile; Prematurity.

\begin{abstract}
Resumo
A mortalidade infantil (MI) é causada por uma junção de fatores biológicos, culturais, sociais e de falhas no sistema de saúde. No país, é possível observar que o controle da MI ainda não está evidente. Este estudo objetivou identificar as principais causas de internação hospitalar em uma Unidade de Terapia Intensiva Neonatal no ano de 2012 e estratificar as características dessa população. Trata-se de um estudo observacional transversal documental. Feita análise de 393 pacientes através dos resumos de alta neonatal e dados oficiais de óbito no período de janeiro de 2012 a dezembro de 2012. Os dados foram tabulados no programa "Originlab data analysis" e formatados no programa Excel. A prematuridade representou a principal causa de internação e óbito neonatal identificada no trabalho. Baixo peso ao nascer, idade gestacional inferior a 34 semanas e o tempo de internação hospitalar também foram características analisadas favorecendo um maior risco de óbito. Esforços para melhor estratificação de dados dos perfis epidemiológicos nacionais são importantes para melhor atenção a essa faixa etária neonatal.
\end{abstract}

Palavras chave: Mortalidade Infantil. Perfil epidemiológico. Prematuridade. 


\section{INTRODUCTION}

The infant mortality (IM) is caused due to a combination of biological, cultural, social events and flaws in the health system. Changes made in the conditions of health in Brazil during the 20th century caused a great impact over the infant mortality and morbidity, some examples were the decrease of infectious and parasitic diseases, improvement in life quality, basic sanitation facilities and drop of fecundity, along with technological advances, mainly in immunization, oral rehydration therapy and the increase of breastfeeding prevalence ${ }^{1,6,7}$.

The rate of infant mortality (RIM) is one of the most important indicators of health universally used to measure the level of health of a population and, indirectly, its development and its quality of life ${ }^{8}$. It is internationally standardized being referred as a number of deaths in under one-year-old children over the number of live births (multiplied by 1000), indicating the risk of a live born coming to death.

According to Belo Horizonte's Health Department, the RIM in Brazil faces a decreasing period, in 1980 it was 78,5 per 1000 live births and in 2005 it was $21,2 / 1000$. It is possible to notice that between 1990 and 2000, the infant mortality dropped from 47,1 to 26,8 death in under one year old children for each one thousand live born, being highlighted a slowdown form this period, coming to 19,3 in $2007^{4}$. However, the indexes are still high once compared to developed countries such as Japan, Canada and Cuba with values of 3 and 10/1000 live born ${ }^{6}$.

The decrease mentioned in the country occurred mainly at the age over one month old, especially with the control of infectious diseases. Although, the success in the mortality control in newborns (NB) is still not evident. The neonatal fraction corresponds to two thirds of the infant mortality ${ }^{9}$.

The higher attention in the neonatal period for the formulation of infant mortality is raising many studies about the causes and decisive factors of deaths in this period ${ }^{1,6,8,12,14}$.

Data provided by the Ministry of Health showed that $70 \%$ of deaths of NB occur for preventable causes, as lack of adequate attention to the woman during pregnancy, in the birth and also to the fetus and to the baby. According to Araújo et al, (2005), the birth weight and gestational age are the more important isolated factors related to neonatal death. In addition the mortality is directly linked to education, familiar income standard, the access to health services, the offer of treated water and sewage and the level of information of the mothers ${ }^{2,4,5}$.
The availability of epidemiological information allows changes in the actions of neonatal assistance and improvement in the system of health service.

The objective of the present study was to identify the main causes of hospital admissions in a Neonatal Intensive Care Unit (NICU) and stratify their characteristics of this population, correlating epidemiological local data with national data.

\section{METHODS}

The research was a Documentary Crosssectional Observational study, in which data were collected in a Neonatal Intensive Care Unit in Campos dos Goytacazes, RJ.

It were analyzed 393 medical records concerning the summary of the neonatal discharge and official records of deaths, done in the period of January of 2012 to December of 2012.

The patients were divided according to month and the reason for the hospital admission. Which, 319 patients were analyzed through the summary of the neonatal discharge and 74 patients were evaluated by the official data of death.

After analyzes of the causes of hospital admission, the 319 medical records concerning the summaries of the neonatal discharge were stratified according to qualitative and quantitative characteristics of the neonate.

Among the qualitative characteristics it is presented: gender, relation weight and gestational age: small for gestational age (SGA), apropriate for gestational age (AGA) and big for gestational age (BGA), type of birth, use of reanimation and procedures of reanimation.

And for the quantitative characteristics the research stressed: lenght of hospital stay, age of the mother, number of pregnancies, number of children, number of pre-natal appointments, conditions of birth (APGAR in the $1^{\text {st }}$ and $5^{\text {th }}$ minute), gestational age, weight of the NB, height and cephalic perimeter.

For comparison of the obtained results, it were used statistics documents with the total of 539 admitted patients in the same Intensive Care Unit during the year of 2011.

For the conducted research, it was not showed any risk to the population in study, once the survey was documental.

For data collecting, the information in the records was compiled in a standardized form and the research was authorized by the management of the clinic of the Hospital. 
The data were tabulated with the help of the program "Originlab data analysis" (8.5 version), and presented in graphics elaborated in the Excel Program. The collected data were showed through a descriptive statistics, presented in frequency of occurrence of each variable to be expressed in absolute numbers and percentage. The intersection of the outcome with the outcome secondary variables (bivariate analysis) was done, and also an correlation analysis was performed.

\section{RESULTS AND DISCUSSION:}

For a comparative analysis with the obtained results in the research during the year of 2012, the total number of patients who had discharge and NB who died during the year of 2011 were also quantified.

A total of 485 newborns were admitted and had discharge during all the year of 2011. Besides adding the 54 admissions and deaths in the same period. Being calculated the total of 539 admitted patients in the Intensive Care Unit in study.

For the year of 2011, there was an expressive number of patients that obtained discharge (485 patients), representing $89,99 \%$ of all admitted patients. The deaths (54 newborns), correspond to a percentage of $10,01 \%$ of the admitted ones in this period.

For the year 2012, it were analyzed 319 patients that were discharged and 74 patients that died, totalizing 393 admitted patients in the year of 2012.

The study revealed a greater percentage of admitted patients that were discharged, numbering $81,18 \%$ of the NB, the deaths reached a percentage of $18,82 \%$ of the population in study.

Comparing the results found in the research with the year 2011, it is possible to identify the total number admitted in the year of 2011, over to the 393 patients in relation to the year 2012. In addition to checking the increase in the percentage in the number of deaths, of $10,01 \%$ in the year of 2011 , to $18,82 \%$ in the year of 2012 .

The statistic monitoring of the birth was a significant advance in the epidemiological area, allowing the knowledge of who is born, how, where and under what conditions. This was possible after 1990 through Live Births Information System implemented by the Ministry of Health- Brazil ${ }^{11}$.

To follow the population in study made it possible to trace statistics data, to point a neonatal mortality framework reaching $18,82 \%$ of this population. Statistics analysis in another epidemiological study carried out by Granzotto et al., (2012a) evaluating the profile of the admitted patients in an Intensive Care
Unit in the years of 2008, 2009 and 2010 found a number of NB who died during the neonatal period in a population studied similar to $15,3 \%, 13,4 \%$ and $7,8 \%$ respectively in the years of research.

Were analyzed specifically the 319 NB admitted in aim to stratify the main causes of hospital admissions of them.

The causes were divided in three main ones: tachypnea, prematurity and "other causes"; to promote a better dealing with the results. Refering "other causes" comes to a group of reasons of admissions broadly varied, since congenital malformations, respiratory distress syndrome, big for gestational age (BGA), hypoglycemia, digestive bleeding, infectious diseases as toxoplasmosis and syphilis.

However, none of these reasons reached a significant percentage as the causes of prematurity and tachypnea which corresponded to $42 \%$ and $39 \%$ respectively, compared to $19 \%$ of "other causes" in the total of NB admitted.

In this case, the neonatal death was analyzed through official data of deaths, also being pointed out the prematurity as the main cause of death, followed by birth asphyxia. In 74 of deaths, $64,86 \%$ was related to prematurity and just $16,21 \%$ is due to birth asphyxia.

The other $18,93 \%$ of death indicated as unknown cause refers to the deaths in the months of November and December that had not been recorded in the official data of death of the unit.

The findings of the present study reveals prematurity as the main cause of admissions and neonatal deaths corresponding to $46,05 \%$ of the total population in study in the Intensive Care Unit.

Studies in different countries showed that there are many reasons which lead a baby to be born prematurely, especially related to female genital apparatus, placental anomalies and excess of amniotic liquid. Other reasons include: mother's age, maternal infection and primiparity ${ }^{11}$.

Other risks that also converge to premature births are caused by the lifestyle changes in the last decades, such as alcohol and smoking, social and occupational stress, inadequate nutrition and other conditions in which the interventions to a healthy pregnancy should occur before the conception'.

Through these statements, there is no doubt that the greater risks of neonatal mortality are frequently associated to the quality of pre-natal and the service at the birth and the attention given by the $\mathrm{NB}^{1}$. Besides, the prematurity comes as a situation of abnormality in the birth, asking for a greater investment 


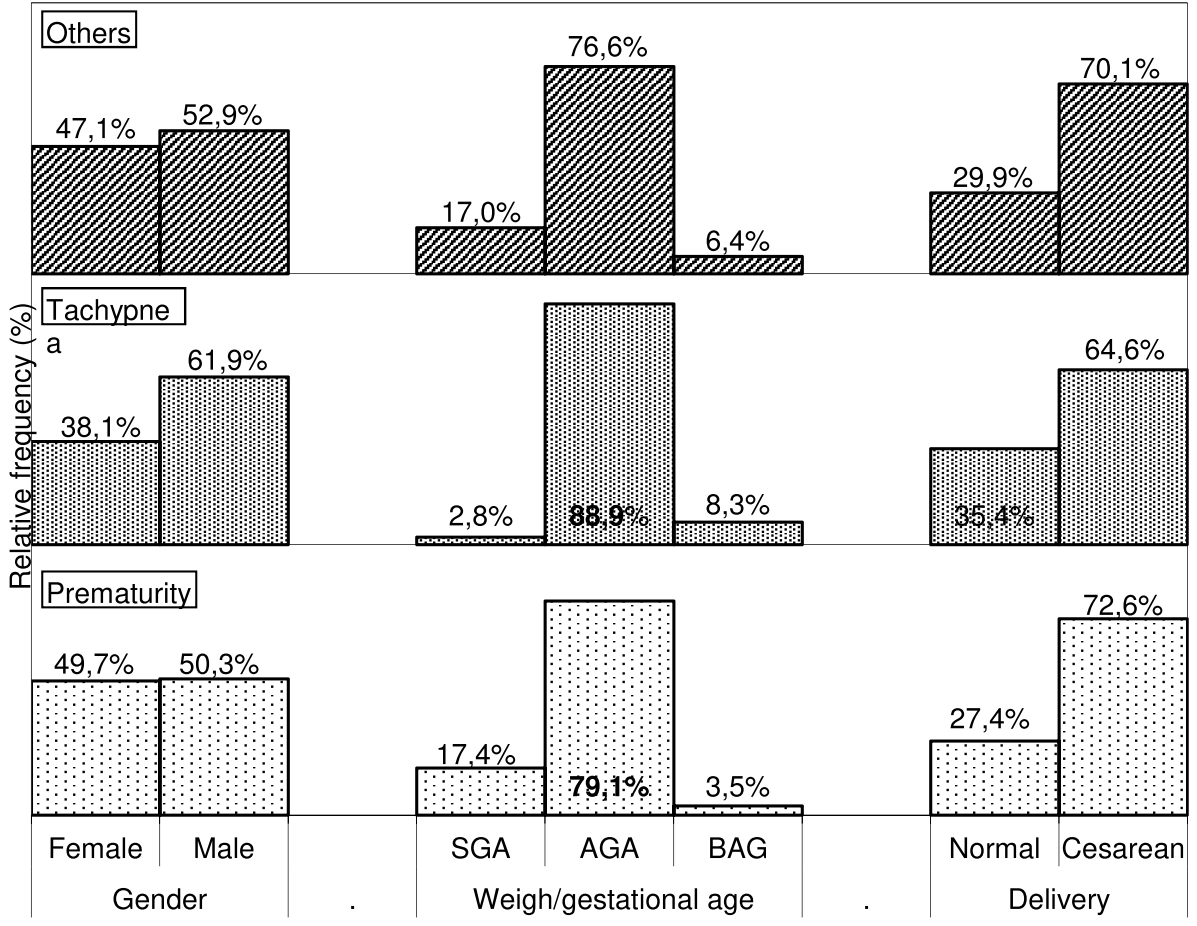

Figure 1: Relative frequency of gender, weight/ gestational age and the type of delivery with the leading causes of hospitalization at the Intensive Care Unit in 2012. of technological and human resources. The lack of Intesive Care Units may make it difficult to prevent inevitably potential deaths ${ }^{9}$.

Due to the data found in the research, prematurity and tachypnea are the main causes of hospital admission. Through the first results, the NB were again stratified according to their qualitative and quantitative characteristics, making it possible to trace an epidemiological profile of the patients that were kept admitted during the year of 2012 .

For qualitative analysis, Figure 1 show an association of newborn separated in hospital admission causes and relative frequency (\%) of male and female, in relation to weight/gestational age (SGA, AGA, BGA) and the type of birth (normal or cesarean).

In the research it was possible to identify a great percentage, independently of the cause of hospital admission, of male in the Intensive Care Unit. It was also found a greater presence of newborns apropriate in relation to his weight to his gestational age and a greater percentage in cesarean births.

Associating these characteristics with the causes of hospital admission, it is clear that there is no exclusive correlation to gender, weight/gestational age relation or the type of birth with a specific cause of admission in this Neonatal Intensive Care Unit.

In other research made by Granzotto et al., (2012b), also points out the male predominance in number of admissions, granting $57 \%$ of the patients, and that the NB of this gender had a higher risk of death in relation of female.

In the same research, Granzotto et al., (2012b), also highlights a percentage of $62 \%$ of cesareans. Many studies shows that the mortality in prematures who are born in surgical birth is lower from the one who are born in normal birth ${ }^{3,8,15}$.

Stratifying qualitative characteristics, was also highlighted the use of reanimation an the used ways for reanimation. The results are shown in Figure 2.

In all causes of admissions, not using the reanimation equipment was predominant, with percentages of $54,05 \%$ for other causes, of $65,96 \%$ for tachypnea and of $57,14 \%$ for premature newborns. However, in the cases where medical intervention was necessary, the oxygen mask was the most used way of reanimation.

Araújo et al., (2005) in his study about neonatal mortality, also shows a higher percentage of live newborns that did not use any type of reanimation.

To initiate the quantitative analysis, it is emphasized the duration of admission, who obtained prematurity as the main cause in which was needed a longer time of hospitalization of the NB, as it shows in Figure 3.

Araújo et al., (2005); Granzotto et al., (2012b) in their researches showed an average between 17 


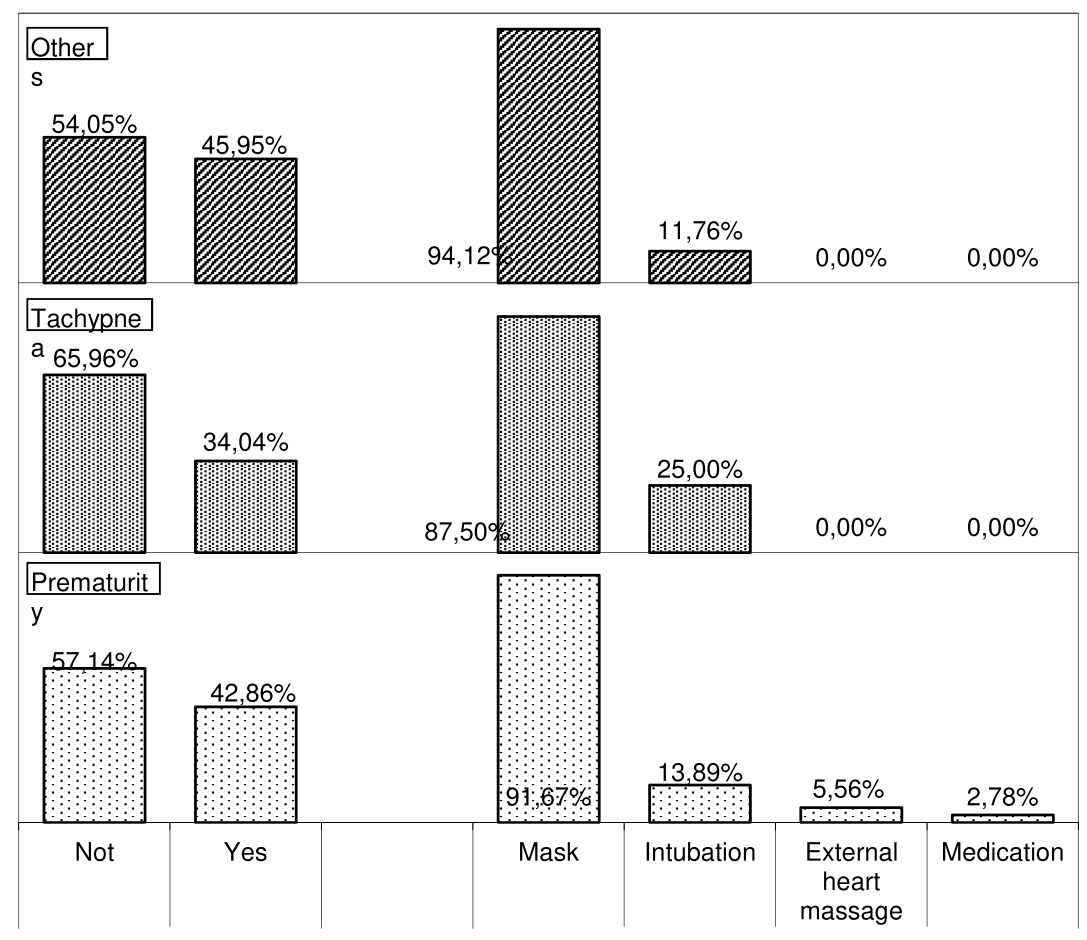

Figure 2: Relative frequency (\%) of causes of hospitalization with the the need for resuscitation in the Neonatal Intensive Care Unit.

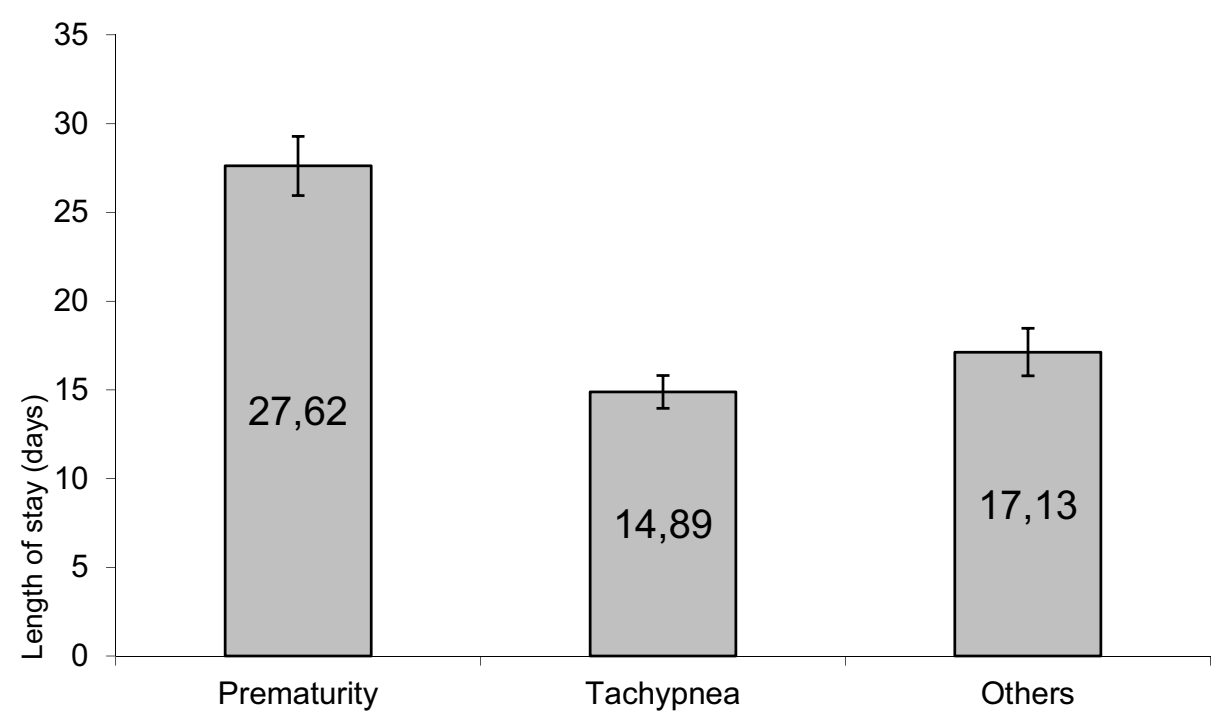

Figure 3: Length of stay (in days) and the causes of hospitalization in the Neonatal Intensive Care Unit.

and 19 days of admission, respectively. Namiiro et al., (2012) emphasizes a longer period of seven days. All indicating that the higher the time the greater is the risk of death, which confirms with this research.

Another analysis was the relative frequency of the number of hospitalizations and discharges with the causes of hospitalization.
The largest percentage of admitted patients was referring to the month of July with tachypnea, representing $19 \%$ of the 63 admitted patients for this reason. And also the month of July showed a greater number of discharges, also for the same reason. It was shown even more, the tachypnea with the shortest time of admission. 
Other causes kept the quantity approximately linear with the admitted patients and those who were discharged, with a slight exception for the month of July, in which "other causes" was highlighted in quantity of admissions $(15,4 \%)$.

The age of the mother also kept approximately the same in the three leading causes of admission. The tachypnea was among the causes, the average younger (21,33 years).

The extremes of age (under 19 years) have been associated with increased risk of IM by its association with prematurity and low weight at birth. In Brazil, the percentage of pregnant teenagers $(10-19$ years old $)$ went from $23 \%$ in 1996 to $21,6 \%$ in $2005^{6}$.

Another important factor in the study was the number of pre-natal visits, as it shows in Figure 4. The pre-natal visits is a technology used to reduce the mother's and fetal risks with a direct repercussion in neonatal mortality ${ }^{8}$.

In the study it was found a lower percentage of prenatal visits for premature's mothers (3-6 visits) compared to the other frequencies of visits (over 7 visits). But in general, evidenced a very low percentage of mothers who had less than 3 prenatal consultations.

In a similar study, Granzotto et al., (2012b), also shows a low percentage of mothers which did not have prenatal visit ( $3 \%$ of his study) and emphasize that the NB of mothers of no pre-natal visit had eight times higher chances of death when compared to the mothers who had six or more visits.

Araújo et al., (2005) points out the absence of pre-natal as being the most important variable related to neonatal death for being associated to a great number of obstetric and neonatal occurrence which resulted the death of the NB.

The Ministry of Health recommends the minimum of six pre-natal visits, being divided: one in the first quarter, two in the second quarter and three in the third gestational quarter. In an attention evaluation of prenatal in Brazil, it was revealed an average of four prenatal visits for women who had the birth by the Public Health System (SUS). It is important to see the necessity of an increase of five millions of visits a year for each woman who had six visits ${ }^{13}$.

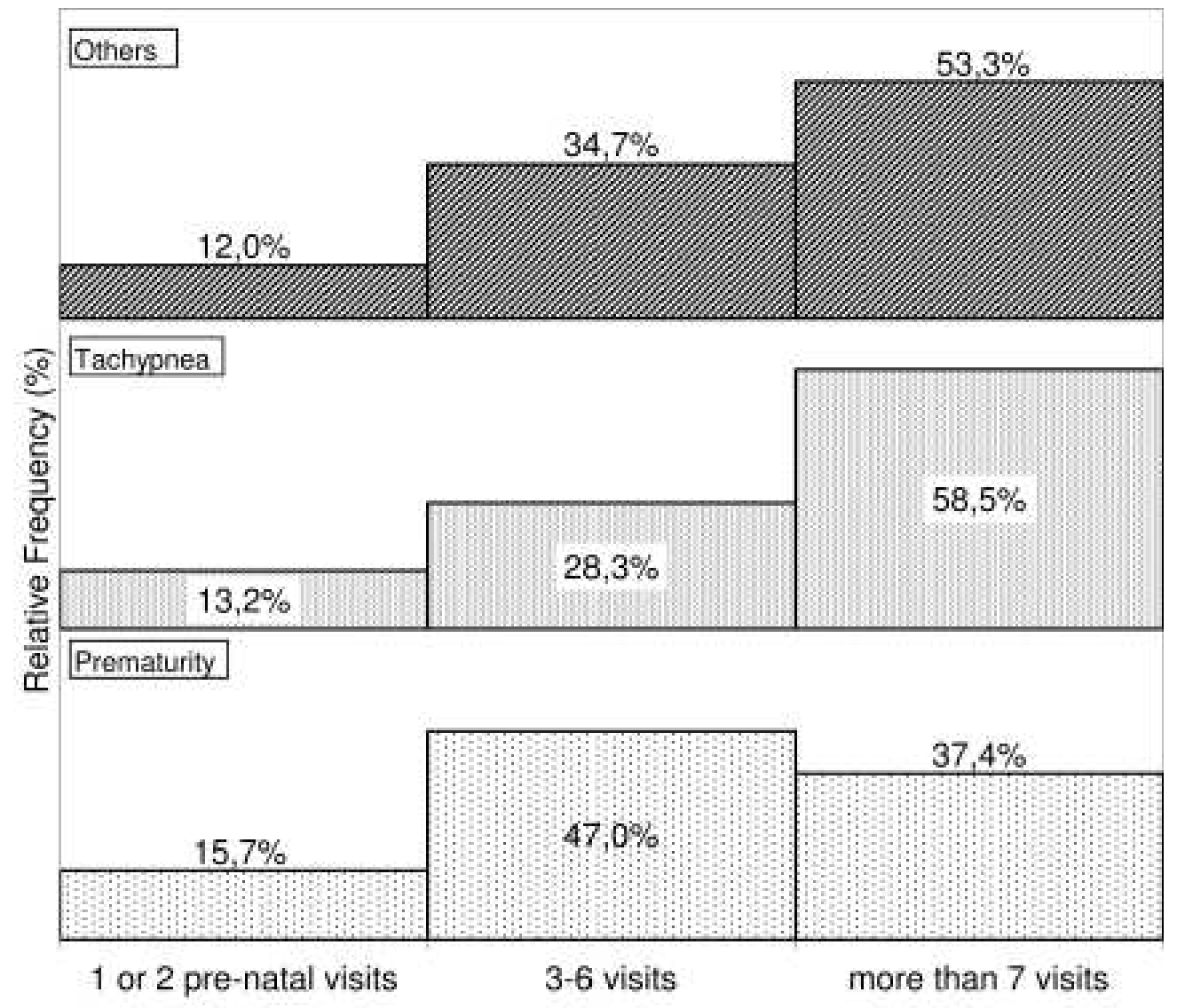

Figure 4: number of antenatal care associated with the leading causes of hospitalization in the NICU. 
About the Apgar, it is a valid score to characterize some type of occurrence to the birth and it is a parameter for a long time prognostic mainly to Apgar inferior to seven in the $5^{\text {th }}$ minute of life .

For the research in study, all the causes of admissions obtained an average of Apgar approximately similar in the $1^{\text {st }}$ and $5^{\text {th }}$ minute. Being the $1^{\text {st }}$ minute the average of Apgar 6.5 and in the $5^{\text {th }}$ minute an average of Apgar 8. No significance checked for the different causes of admission.

Granzotto et al., (2012b), also takes into account the importance of Apgar for the neonatal mortality.
He focuses that the Apgar which presents values lower than 3 in the $5^{\text {th }}$ minute of life have a 5 time higher risk approximately.

Although the Apgar is not an adequate score for reanimation in the birth room, it is known that an NB with a low Apgar at birth shows a greater difficulty in extrauterine adaptation, making it worse the base pathologies as hyaline membrane disease ${ }^{8}$.

The Figure 5 brings another important characteristic analyzed in the study, the gestational age of the mother of the admitted patients in the Intensive Care Unit.

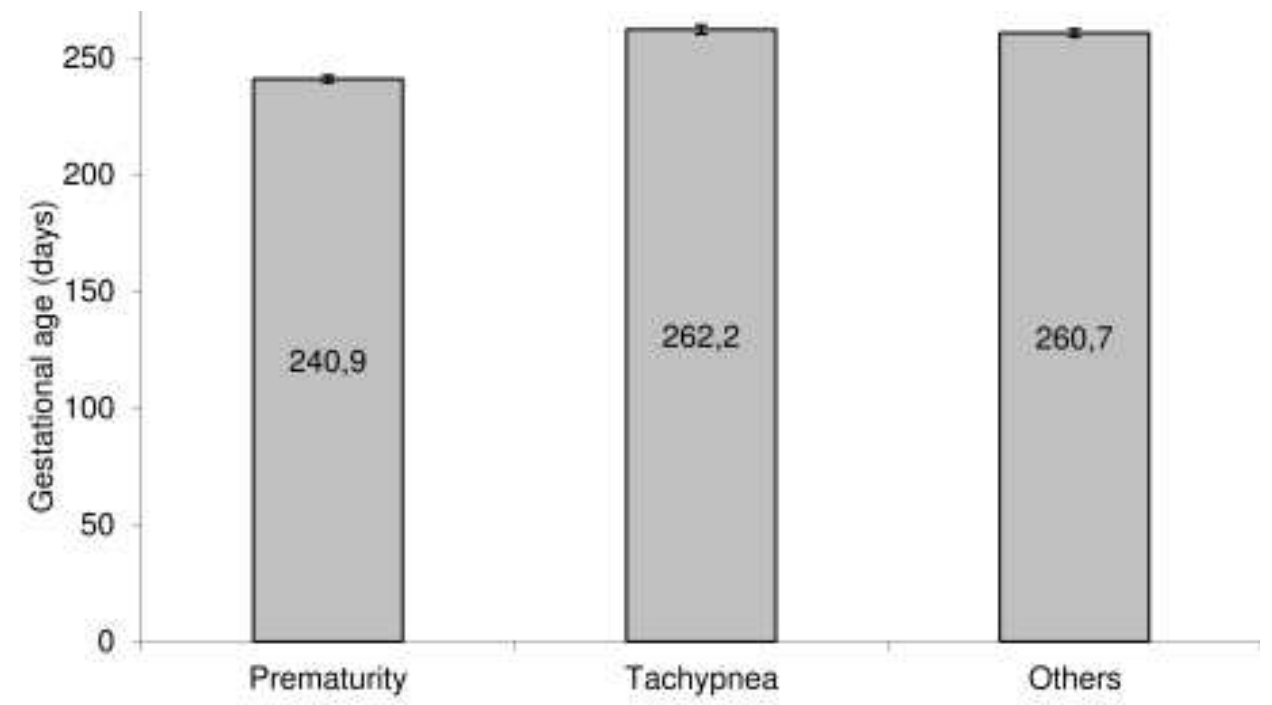

Figure 5: gestational age (in days) and the main causes of neonatal hospitalization at the NICU in 2012 .

The Figure shows gestational age as an important cause for premature birth and admission of the newborn in the NICU. The average gestational age in the premature NB was of 34 weeks (240 days), being the admitted newborn with tachypnea and other causes hade an average of 37 weeks of pregnancy (260 days).

Other researches also pointed the gestational age inferior to 34 weeks with a greater risk of death, as Araújo et al., (2005) who points out a risk of death 6.8 higher than the other NB.

To a broader understanding, it was also given focus in the weight, height and cephalic perimeter $(\mathrm{CP})$ of the newborns.

Most of the NB obtained weight over to 2.000 gr, although the prematurity presented the lowest values of weight found in the research, being the weight of $750 \mathrm{gr}$ the lowest observed (figure 6).
In the analysis it was also clear in the premature $\mathrm{NB}$ a lower height compared to the admitted newborns with tachypnea or other alterations. And it also matches for the values found in the cephalic perimeter of the $\mathrm{NB}$, being the average of $30 \mathrm{~cm}$ of $\mathrm{CP}$ in the premature.

According to Rocha et al., (2011) the prematurity and the low weight at birth are the most associated facts to neonatal mortality. In another study of Araújo et al., (2005) the prematurity and the low weight contributed to $77 \%$ and $77.7 \%$ of deaths, respectively.

\section{CONCLUSIONS}

An increase of 100 grams in the average weight at birth of the NB is associated with a reduction of 30 to $50 \%$ of neonatal mortality, pointing the importance of programs which stimulates the nutritional state of the mother ${ }^{2}$. 


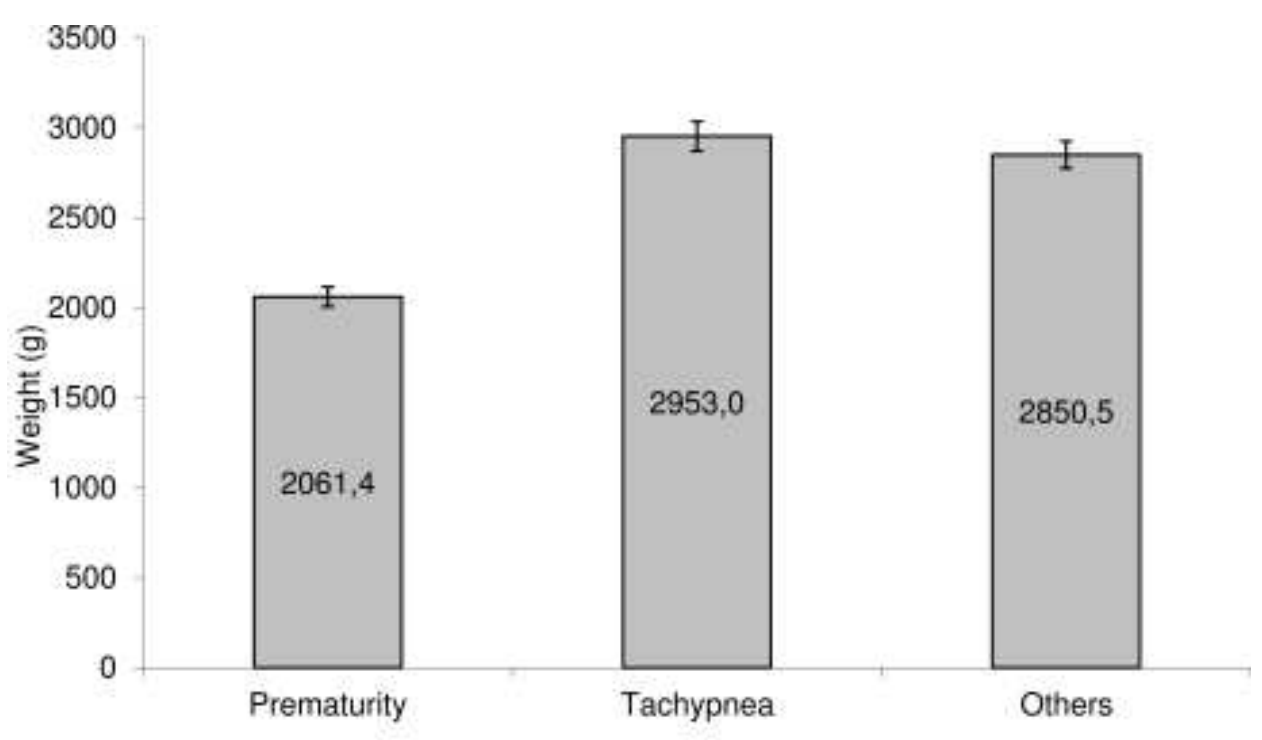

For a change in the neonatal mortality profile, it is necessary the elaboration of a set of measures: adequate assistance to the pre-natal, as the number of visits interfere in the neonatal deaths; carrying safe births, with equipment to the assistance of NB, once identified that the Apgar, weight at birth and gestational age are risk factors to death too.
Many researches show that the adequate attention to the woman during the pregnancy, in the birth and to the $\mathrm{RN}$ is the significant portion of neonatal deaths. Gynecological visits, immediate assistance to the newborn are determining for the survival and life quality of the child.

\section{BIBLIOGRAPHICALREFERENCES}

1. Almeida WS, Szwarcwald CL 2012. Mortalidade infantil e acesso geográfico ao parto nos municípios brasileiros. Rev. Saúde Pública 46: 68-76.

2. Araújo BF, Tanaka AC, Madi JM, Zatti H 2005. Estudo da mortalidade de recém-nascidos internados na UTI neonatal do Hospital Geral de Caxias do Sul, Rio Grande do Sul. Rev. Bras. Saúde Matern. Infantil 5:463-469.

3. Bettegowda VR, Davidoff MJ, Damus K, Callaghan WM, Petrini JR 2008. The relationship between cesarean delivery and gestational age among US singleton births. Clin. Perinatol 35:309-323.

4. Brasil Ministério da Saúde [database on the internet]. Diagnóstico no Brasil, mortalidade em declínio. c2012a - [cited 2014 Aug 24]. Available from: http://www.saude.mppr.mp.br/arquivos/File/kit_atencao_perinatal/pactos/

pacto_reducao_mortalidade_infantil_nordeste_e_amazonia_legal.pdf

5. Brasil Ministério da Saúde, Secretária de atenção à saúde, Departamento de ações progmáticas e estratégicas [database on the internet]. Manual AIDPI neonatal. c2012b - [cited 2014 Set 02]. Available from: http://bvsms.saude.gov.br/bvs/ publicacoes/manual_aidpi_neonatal_3ed_2012.pdf

6. França E, Lansky S. Mortalidade Infantil e Neonatal no Brasil: Situação, Tendências e Perspectivas. Relatório elaborado por solicitação da RIPSA [database on the internet]. Belo Horizonte: Departamento de Medicina Preventiva e Social UFMG. c2008 - [cited 2014 Aug 23]. Available from: www.abep.nepo.unicamp.br/encontro2008/docsPDF/

ABEP2008_1956.pdf

7. Granzotto JA, Mota DM, Dias CM, Teixeira RF, Filho JCM, Tiecher GB, Pilecco AJL, Gonçalves ER 2012a. Análise do perfil epidemiológico das internações em uma unidade de terapia intensiva neonatal. Revista da AMRIGS 56:304-307.

8. Granzotto JA, Fonseca SS, Lindemann FL 2012b. Fatores relacionados com a mortalidade neonatal em uma Unidade de Terapia Intensiva neonatal na Região Sul do Brasil. Revista da AMRIGS 56:57-62.

9. Maia LTS, Souza WV, Mendes ACG 2012. Diferenciais nos fatores de risco para mortalidade infantil em cinco cidades brasileiras: um estudo de caso-controle com base no SIM e no SINASC. Cad. Saúde Pública 28:2163-2176.

10. Namiiro FB, Mugalu J, Mcadams RM, Ndeezi G. Poor birth weight recovery among low birth weight/preterm infants following hospital discharge in Kampala, Uganda. BMC Pregnancy and Childbirth [serial on the internet]. 2012 [cited 2013 Feb 13];12 [about 4p.]. Available from: www.biomedcentral.com/1471-2393/12/1 
11. Ramos HAC, Cuman RKN 2009. Fatores de risco para prematuridade: pesquisa documental. Esc Anna Nery Rev. Enferm 13:297-304.

12. Ray JG, Urquia ML, Berger H, Vermeulen MJ 2012. Maternal and Neonatal separation and mortality associated with concurrent admissions to intensive care units. Canadian Medical Association Journal-CMAJ 184:56-62.

13. Rocha R, Oliveira C, Silva DKF, Bonfim C 2011. Mortalidade neonatal e evitabilidade: uma análise do perfil epidemiológico. Rev. enferm. UERJ 19:114-120.

14. Sus, Ministério da Saúde. Proporção de internações hospitalares por grupo de causas [database on the internet]. Brasília (DF). c2008 [updated 2008; cited 2013 Feb 20]. Available from: http://www.ripsa.org.br/fichasIDB/ record.php?node $=$ D. $13 \&$ lang $=$ pt \&version $=$ ed 3

15. Verhagen AA, Janvier A, Leuthnner SR, Andrews B, Lagatta J, Bos AF, Meadow W 2010. Categorizing neonatal deaths: a cross-cultural study in the United States, Canada, and The Netherlands. J.Pediatria 156:33-37. 